\title{
Dual semantic encoding of homographs and homophones embedded in context
}

\author{
ROBERT E. WARREN \\ Columbia University, New York, New York 10027 \\ and \\ NATALIE T. WARREN \\ Princeton University, Princeton, New Jersey 08540
}

\begin{abstract}
Dual encoding of homographs and homophones was inferred from the intrusion of their alternative meanings across trials in two experiments using a modified Brown-Peterson paradigm. In Experiment 1 subjects heard a word triad and then engaged in a 10.5-sec distractor task. Written recall was then demanded. $\mathrm{On}$ context trials a homophone with alternative meanings belonging to two distinct categories was embedded in a triad biasing one meaning, e.g., helpless, /wik/, fragile. On the next trial, words from the category of the other meaning were presented, e.g., year, month, decade. A significant number of intrusions of the alternative coding of the homophone, e.g., WEEK, across the category boundary were observed. Experiment 2 employed visual presentation of embedded homographs, e.g., plunged, jumped, DOVE, and oral recall but was logically similar to Experiment 1 . Intrusions of the alternative codings of homographs across category boundaries, e.g., pigeon, sparrow, $/ \mathrm{d} \Lambda \mathrm{v} /$, were again noted.
\end{abstract}

The encoding of ambiguous words, such as homographs and homophones, has recently become a matter of some dispute. Although actual instances of homographs and homophones are rare in English, these words have been the focus of wider discussions of semantic encoding, since they provide extreme cases against which more general theories can be tested. It has been argued, on the one hand, that only one of the alternative meanings of such words is encoded and stored and that the particular meaning encoded is determined by the semantic context within which the word is embedded (Lashley, 1951). It is certainly true that one is usually aware of only one meaning for such words. On the other hand, this subjective impression does not rule out the possibility that dual semantic representation is employed at an early stage of processing and that only at some later point is a single meaning selected.

In an experimental study of this question, Conrad (1974) presented subjects with sentences containing homonyms such as "The sailors enjoyed the port" or "The sailors drank the port," then had them name the color in which a visually presented test word such as WINE or HARBOR was printed. It has been previously argued that the degree of interference with color naming produced in this situation is directly related to the degree of activation in memory of the word serving as the carrier for the color (Warren, 1972, 1974). Conrad

Requests for reprints should be sent to R. E. Warren, Department of Psychology, Columbia University, New York, New York 10027. The authors wish to thank Michael Hess for testing subjects for Experiment I. Funds for Experiment II were provided by a grant from the Columbia University Council for Research in the Social Sciences. found that both WINE and HARBOR produced more interference with color naming when tested after either the ambiguous or unambiguous presentation of PORT than when tested after unrelated material. This result suggests that, at least initially, both meanings of a homophone are activated during its encoding.

Other experimental work on the dual-encoding hypothesis has not produced such congenial results, however. In a recognition memory study, Light and Carter-Sobell (1970) found reduced recognition of words such as jam when presented in one context, e.g., traffic jam, and tested in another, e.g., strawberry jam, some 6-7 min later. This suggests that traces of the dual encoding of such words, if indeed they exist, do not persist over this interval. Similarly, Schvanaveldt, Meyer, and Becker (1974), using facilitation in a lexical decision task as their measure of encoding, found no indication that words semantically related to an alternative, unselected, meaning of a homonym embedded in context had been activated during the homonym's presentation.

The present experiments examine the encoding of homographs and homophones by studying the intrusion of their alternative meanings across trials in a modified Brown-Peterson paradigm. In this paradigm, subjects are presented on each trial with three words drawn from a single semantic category. After triad presentation, subjects are given a rehearsal preventing task and after some fixed interval are required to reproduce as many of the words as they can. Wickens (1970) has argued that the level of recall observed in this paradigm is dependent on the degree to which the subject can discriminate between the encoded representations of the 
Table 1

Homophones, Context, and Expected Intrusions

\begin{tabular}{|c|c|c|c|c|c|c|c|}
\hline \multicolumn{3}{|c|}{ Homophone Context Trial } & \multirow{2}{*}{$\frac{\begin{array}{c}\text { Control } \\
\text { Substitute }\end{array}}{\text { carve }}$} & \multicolumn{3}{|c|}{ Succeeding Critical Trial } & \multirow{2}{*}{$\begin{array}{l}\begin{array}{l}\text { Expected } \\
\text { Intrusion }\end{array} \\
\text { pear }\end{array}$} \\
\hline cut & PARE & chop & & apple & peach & prune & \\
\hline fragrance & SCENT & bouquet & stink & dollar & penny & nickle & cent \\
\hline carrot & BEET & potato & turnip & hit & slap & strike & beat \\
\hline dined & ATE & consumed & drank & four & one & seven & eight \\
\hline helpless & WEAK & fragile & tired & year & month & decade & week \\
\hline second & HOUR & minute & day & his & your & their & our \\
\hline earth & SUN & venus & saturn & father & sister & uncle & son \\
\hline daughter & AUNT & cousin & niece & spider & bee & moth & ant \\
\hline touched & READ & saw & smelled & blue & yellow & black & red \\
\hline jingle & PEAL & chime & tinkle & rind & shell & bark & peel \\
\hline skin & FUR & hide & pelt & oak & pine & elm & fir \\
\hline tune & HYMN & melody & note & her & it & them & him \\
\hline hollow & BARREN & void & drained & king & duke & earl & baron \\
\hline prince & KNIGHT & queen & czar & morning & noon & evening & night \\
\hline rasp & CREAK & grate & grind & river & brook & stream & creek \\
\hline
\end{tabular}

words from the current triad and those from the previous triads. If the category from which words are selected is shifted from trial to trial, the subject is able to exclude words from a previously presented category from recall of the current category on the basis of the semantic characteristics that define the two categories. Since intrusions from previous trials are a common source of error when category cues are absent, their elimination results in increased recall.

In the present study, the dual category membership of homographs and homophones is exploited as a means of studying their encoding. On context trials in Experiment I, a homophone whose alternative meanings belong to two distinctly different categories is presented embedded in an auditory word triad that biases one interpretation of the homophone, e.g., helpless, /wik/, fragile. In the immediately subsequent critical trial, words from the category of the alternative meaning are presented, e.g., year, month, decade. Written recall is demanded on each trial. If only a single meaning of a homophone is encoded, no intrusions of the homophone across the category boundary should occur, since the subject should be able to eliminate from recall any word not from the presented category. On the other hand, if both meanings of a homophone are encoded, occasional intrusions of the alternative coding, e.g., WEEK, could be expected. Experiment II applies the same logic to the problem of homograph encoding.

\section{EXPERIMENT I}

\section{Method}

Subjects. Subjects were 50 students enrolled in undergraduate psychology courses at Columbia University, who received supplemental credit for their participation.

Material and procedure. Subjects were tested in small groups for a single 45-min session and heard the prerecorded stimuli for the experiment over a loudspeaker. Stimuli consisted of homogeneous word triads drawn from various categories, e.g., apple, peach, and prune drawn from the category fruits, and the two-digit numbers $10-90$, excluding 50 , which were used in a rehearsal preventing task adapted from Posner and Rossman
(1965). On each trial in the experiment, subjects heard the word READY, followed by a word triad and seven two-digit numbers, then the word RECALL. All material was presented at the rate of one word or number every $1.5 \mathrm{sec}$.

Subjects were instructed to listen to the word triad, perform a classification task on each number as it was given, and then write down the word triad for that trial. In the classification task subjects were to classify each number as high $(>50)$ or low $(<50)$ and as odd or even. Fifteen seconds were allowed between trials for recall and subjects were encouraged to write down three words for each trial even if they were unsure of a particular word. One practice trial and 52 experimental trials were given.

Subjects recorded both triad recall and the results of the classification task on individual-trial response slips. Every slip had a row of seven boxes each containing the capital letters $\mathrm{H}, \mathrm{L}, \mathrm{O}$, and E. Below these boxes was a separate blank marked RECALL. Classification of a number was indicated by circling the letter $\mathrm{H}$ or $\mathrm{L}$ and $\mathrm{O}$ or $\mathrm{E}$ in the appropriate box. Once subjects had completed recall for a trial, they turned to a new response slip and were not permitted to change or refer back to any previous trial's recall.

Two groups of 25 subjects were tested. For both groups the 52-trial series was broken down into 26 successive two-trial blocks, within which all the words were drawn from a single category. For 15 of the blocks presented to the test group, the second word on the second trial in the block was a homophone. One of the possible interpretations of this homophone was a word belonging to the current block category, while an alternative interpretation was a word belonging to the category of the immediately following block. For example, the word AUNT in the context triad DAUGHTER, AUNT, COUSIN (category "relatives") is one interpretation of the homophone that could also be encoded as ANT if substituted in the critical triad SPIDER, BEE, MOTH (category "insects"). The control group received the same list as the test group, except that other category members were substituted for the homophones in the 15 context blocks.

The homophones used and the substitutes presented to the control group are shown in Table 1 along with the other words in the context triads and the immediately succeeding critical triads. Homophones were selected from Whitford's (i966) list on the basis of their membership in two distinct semantic categories. Additional category members were generated by the experimenters.

Results

Homophone recall in the context blocks was first 
examined separately for the test group. Recall errors occurred in $26.7 \%$ of the instances in which homophones were presented. On those trials where homophones were recalled, $91.3 \%$ were recalled in the form matching the context block category, e.g., cut PARE chop; $7.6 \%$ were recalled in the alternative form matching the succeeding critical block, e.g., cut PEAR chop; and $1.1 \%$ were recalled in forms matching neither category, e.g., cut PAIR chop. Recall of alternative interpretations in context blocks occurred for 6 of the 15 homophones used: PARE/PEAR (10 out of 25 instances), PARE/PAIR (2/25), BEET/BEAT (3/25), WEAK/WEEK (1/25), READ/RED (4/25), PEAL/PEEL $(2 / 25)$, PEAL/PEALE $(1 / 25)$, and CREAK/CREEK $(1 / 25)$.

An examination of control group recall showed that words matching the homophones presented to the test group intruded into recall of $2.1 \%$ of the context block.

For both groups, recall of triads in critical blocks was examined for the intrusion of words matching the alternative coding of the homophone presented to the test group in the immediately previous context block. The appearance of the word CENT in the recall of DOLLAR PENNY NICKEL, for example, was scored as a homophone intrusion. In scoring the protocols of the test group, intrusions on critical trials which were preceded on previous context trials by recall of the homophone in the intrusion configuration were not scored as homophone intrusions. If the instrusion of CENT, for example, had been preceded by recall of FRAGRANCE CENT BOUQUET, instead of SCENT, the intrusion would not have been counted. Likewise, intrusions found in control group protocols which had been preceded in the recall of the prior context block by the production of the matching homophone were not counted. For example, if the intrusion of CENT by a control subject had been preceded by recall of SCENT, even though the individual had never heard that particular word, the intrusion would not have been counted.

Test group subjects had an average of $1.12(\mathrm{SD}=.97)$ homophone intrusions, while control subjects showed an average of $.68(\mathrm{SD}=.69)$ homophone intrusions. The distribution of homophone intrusions across subjects is shown in Table 2. Intrusion frequency scores were transformed using the $\sqrt{\mathrm{x}+.5}$ transform recommended by Myers (1966) for frequency count data, and $a$ one-tailed $t$ test on these scores proved significant $[\mathrm{t}(48)=1.73, \mathrm{p}<.05]$.

A second analysis on intrusion scores for the two groups limited test group subjects to those intrusions which had been preceded by homophone recall in the correct form on prior context trials and excluded, for all subjects, intrusions of those six homophones which had been subject to alternate-form recall by any test group subject on context trials (PARE, BEET, WEAK, READ, PEAL, and CREAK). A $\sqrt{\mathrm{x}+.5}$ transform was used in this analysis, and it was also significant $[\mathrm{t}(48)=$ $1.70, \mathrm{p}<.05)$.
Table 2

Number of Subjects Producing Homophone or Homograph Intrusions

Number of Intrusions Produced

\begin{tabular}{|c|c|c|c|c|c|c|c|c|}
\hline \multirow{2}{*}{$\begin{array}{l}\text { Type of } \\
\text { Intrusion }\end{array}$} & \multirow[b]{2}{*}{ Group } & \multirow[b]{2}{*}{$\mathbf{n}$} & \multicolumn{6}{|c|}{ Produced } \\
\hline & & & 0 & 1 & 2 & 3 & 4 & 5 \\
\hline \multirow{2}{*}{ Homophone } & Test & 25 & 7 & 11 & 4 & 3 & 0 & \\
\hline & Control & 25 & 11 & 11 & 3 & 0 & 0 & \\
\hline \multirow{2}{*}{ Homograph } & Test & 20 & 3 & 7 & 3 & 3 & 2 & 2 \\
\hline & Control & 20 & 10 & 10 & 0 & 0 & 0 & 0 \\
\hline
\end{tabular}

The distribution of intrusions for the various homophones is shown in Table 3. As an estimate of the generality of the results beyond this sample of homophones, a t test considering the individual homophones as the units of analysis collapsing across subjects was performed. A $\sqrt{x+.5}$ transform of the intrusion frequency scores was used. The analysis proved significant $[t(14)=2.33, \mathrm{p}<.025]$.

An item criterion was used in scoring the recall protocols for overall errors (Wickelgren, 1965). Mean errors in the critical blocks for the test and control groups were $13.56(\mathrm{SD}=7.02)$ and $15.40(\mathrm{SD}=8.90)$, respectively. A t test was performed on critical block error scores using a $\sqrt{x+.5}$ transform. The analysis showed no significant difference in overall errors for the two groups $[\mathrm{t}(48)=.70, \mathrm{p}>.10]$. The greater frequency of homophone errors in the test group, then, cannot be attributed to a generally higher error rate for these subjects. As a further check, all critical trial errors were classified as homophone intrusions, other intrusions, and omissions. The test group showed 28,176 , and 135 errors of these types, respectively, while the control group showed 17,214 , and 154. Expressed as a percentage of the total errors committed, the test group made homophone intrusions almost twice as often as did the control group ( $8.3 \%$ as opposed to $4.4 \%$ ).

Table 3

Homophone Intrusions and Generations

\begin{tabular}{ccc}
\hline Homophone & $\begin{array}{c}\text { Test Group } \\
\text { Intrusions }\end{array}$ & $\begin{array}{c}\text { Control Group } \\
\text { Generations }\end{array}$ \\
\hline pear & 5 & 7 \\
cent & 4 & 0 \\
beat & 0 & 0 \\
eight & 5 & 3 \\
week & 1 & 0 \\
our & 1 & 1 \\
son & 0 & 0 \\
ant & 3 & 0 \\
red & 3 & 3 \\
peel & 0 & 0 \\
fir & 0 & 0 \\
him & 3 & 2 \\
baron & 0 & 0 \\
night & 2 & 1 \\
creek & 1 & 0 \\
Total & 28 & 17
\end{tabular}


Table 4

Homographs, Context, and Expected Intrusions

\begin{tabular}{|c|c|c|c|c|c|c|c|}
\hline \multicolumn{3}{|c|}{ Homograph Context Trial } & \multirow{2}{*}{$\frac{\begin{array}{c}\text { Control } \\
\text { Substitute }\end{array}}{\text { rubbish }}$} & \multicolumn{3}{|c|}{ Succeeding Critical Trial } & \multirow{2}{*}{$\begin{array}{r}\begin{array}{r}\text { Expected } \\
\text { Intrusions }\end{array} \\
\mid \mathrm{rI} \cdot \mathrm{fuz} /\end{array}$} \\
\hline garbage & trash & REFUSE & & deny & reject & spurn & \\
\hline steel & bronze & LEAD & copper & pilot & direct & steer & /lid/ \\
\hline delight & charm & ENTRANCE & betwitch & exit & door & access & /en'trans/ \\
\hline alto & soprano & BASS & tenor & trout & salmon & tuna & /bes/ \\
\hline little & tiny & MINUTE & small & second & moment & hour & /mIn'it/ \\
\hline anger & enrage & INCENSE & madden & perfume & fragrance & aroma & /In'sens/ \\
\hline quarrel & brawl & ROW & squabble & line & column & series & /ro/ \\
\hline plunged & jumped & DOVE & leaped & pigeon & sparrow & robin & $/ \mathrm{d} \Lambda \mathrm{v} /$ \\
\hline pig & hog & sow & boar & plant & seed & strew & /so/ \\
\hline sooty & sticky & TARRY & gooey & wait & linger & abide & /tar'i/ \\
\hline wrapped & coiled & WOUND & entwined & gash & cut & bruise & /wund/ \\
\hline abandon & forsake & DESERT & leave & badlands & waste & wilderness & $/ d \in z^{\prime} \partial t /$ \\
\hline active & vigorous & LIVE & dynamic & dwell & reside & inhabit & /IIV/ \\
\hline curtsy & salaam & BOW & kneel & spear & arrow & axe & /bo/ \\
\hline protest & denounce & OBJECT & balk & goal & purpose & aim & $/ \partial b^{\prime} \cdot \mathrm{j} \epsilon \mathrm{kt} /$ \\
\hline
\end{tabular}

\section{Discussion}

As hypothesized, test group subjects showed a significantly greater number of intrusions of the alternate meaning of previously presented homophones into critical block recall than control subjects. No significant difference between the test and control groups in overall performance on the critical trials was apparent.

Examination of test group recall in context blocks indicates that, on the whole, the context provided was sufficient to disambiguate the presented homophones. The analysis based on the exclusion of those homophones subject to misinterpretations still showed the intrusion effect, reflecting the persistence in memory of alternative encodings of a homophone, even after one meaning has been selected for recall.

It appears that, even when encountered in context, both meanings of a homophone are encoded. The alter. native, unselected, encoding apparently retains sufficient strength in memory to intrude into the recall of material presented some time after it has been activated. The length of the interval between actual presentation and intrusion, minimally $45 \mathrm{sec}$, appears sufficient to eliminate the possibility that an actual auditory sensory trace of the homophone is responsible for the intrusions observed, since studies of echoic memory seem to indicate a maximum persistence for such acoustic sensory traces of $10 \mathrm{sec}$ for a tone (Eriksen \& Johnson, 1964) and $2-3 \mathrm{sec}$ for more complex auditory stimuli such as words (Crowder \& Morton, 1969).

\section{EXPERIMENT II}

\section{Method}

Subjects. Forty individuals were recruited from the University of Oregon Cognitive Studies Center pool and were paid \$2 for their participation.

Materials and procedure. Subjects were tested individually in 30-min sessions and viewed the stimuli for the experiment in a dimly lit room. Stimuli consisted of homogeneous word triads, as in Experiment I, and three-digit numbers which were used in a rehearsal preventing task. On each trial in the experiment, subjects heard the spoken word READY and then were shown a slide with three words, in uppercase letters, arranged in a column. This slide remained visible for $3 \mathrm{sec}$ and was then replaced by a slide with a three-digit number. Ten seconds after number presentation, subjects heard the spoken word RECALL.

Subjects were instructed to read each word triad silently and then count backward aloud by threes from the number shown until they heard the word RECALL. Counting was paced by a metronome emitting $1 \mathrm{click} / \mathrm{sec}$ and subjects were told to count back one step on each beat. Prior to the experiment proper, subjects were given practice counting backward from three numbers for $10 \mathrm{sec}$ each at the prescribed rate. At the word RECALL, subjects recalled aloud the triad just shown. Recall was tape reccrded and then transcribed after the experimental session. Ten seconds were allowed between trials for recall, and subjects were encouraged to produce three words for each trial even if they were unsure of a particular word. Two practice trials and 30 experimental trials were given.

Two groups of 20 subjects were tested. For both groups the category from which the word triad was drawn shifted on each successive trial. On 15 of the trials presented to the test group the third (bottom) word of the triad was a homograph. One of the possible interpretations of this word belonged to the current context category, while an alternative interpretation fit the category of the immediately subsequent critical trial. For example, the word SOW presented to the test group in the context triad PIG HOG SOW is a homograph that could also be substituted in the immediately following triad, PLANT SEED STREW. The control group received the same list as the test group, except that other category members were substituted for the homographs on the 15 context trials.

The homographs used are shown in Table 4 along with the other words in the context trials and the immediately succeeding critical trials. Control list substitutes are also shown in Table 4. The homographs used were selected from Whitford's (1966) list so that a homograph's alternative meaning fell into two distinct categories. Additional words in these categories were generated by the experimenters and used to provide context for the homographs.

\section{Results}

Homograph recall on context trials was first ex. amined separately for the test group. Recall errors occurred in $20.0 \%$ of those instances in which homographs were presented. On those trials where homographs were recalled, $85.4 \%$ were recalled in the form matching the context category, e.g., pig, hog, /sav/, and $14.6 \%$ were recalled in the alternative form match- 
Table 5

Homograph Intrusions and Generations

\begin{tabular}{lcc}
\hline Homograph & $\begin{array}{c}\text { Test Group } \\
\text { Intrusions }\end{array}$ & $\begin{array}{c}\text { Control Group } \\
\text { Generations }\end{array}$ \\
\hline refuse & 4 & 1 \\
lead & 0 & 0 \\
entrance & 0 & 0 \\
bass & 4 & 1 \\
minute & 6 & 2 \\
incense & 1 & 0 \\
row & 2 & 0 \\
dove & 4 & 0 \\
sow & 5 & 0 \\
tarry & 2 & 0 \\
wound & 3 & 0 \\
desert & 3 & 2 \\
live & 3 & 3 \\
bow & 3 & 1 \\
object & 0 & 0 \\
Total & 40 & 10 \\
\hline
\end{tabular}

ing the category of the subsequent critical trial, e.g., $\mathrm{pig}, \mathrm{hog}, / \mathrm{so} /$. Recall of the alternative interpretations on context trials occurred for 11 of the 15 homographs used: ROW (12 out of 20 instances), ENTRANCE $(6 / 20)$, BASS $(3 / 20)$, INCENSE $(3 / 20)$, TARRY $(3 / 20)$, DOVE $(2 / 20)$, WOUND $(2 / 20)$, SOW $(1 / 20)$, DESERT $(1 / 20)$, LIVE $(1 / 20)$, BOW $(1 / 20)$.

Examination of control group recall revealed intrusion of words matching homographs shown to the test group on $1 \%$ of the context trials.

In scoring the intrusion on critical trials of alternative forms of the homographs presented to the test group on context trials, rules directly comparable to those set out for Experiment I were followed. Test group subjects had an average of $2.00(\mathrm{SD}=1.59)$ homograph intrusions, while control group subjects showed an average of $.50(\mathrm{SD}=.51)$ such intrusions. Table 2 shows the number of subjects in each group who made homograph intrusions. The frequency of intrusions ranged from zero to five for individual subjects. A one-tailed t test using the $\sqrt{x+.5}$ transform of these scores showed this difference to be significant $[\mathrm{t}(38)=6.47, \mathrm{p}<.0005]$.

A second analysis was done on intrusion scores for the two groups, limited for the test group subjects to those homophone intrusions which had been preceded by recall in the correct form on prior context trials. A $\sqrt{x+.5}$ transform was used. This analysis was also significant $[\mathrm{t}(38)=3.10, \mathrm{p}<.005]$.

The distribution of intrusions for the various homographs is shown in Table 5. As an estimate of the generality of the results on this sample of homographs, a $t$ test considering individual homographs as the unit of analysis collapsing across subjects was performed using a $\sqrt{\mathrm{x}+.5}$ transform of the instrusion frequency scores. This analysis proved significant $[t(14)=4.93$, $\mathrm{p}<.0005]$.

An item criterion was used in scoring overall recall on the critical trials (Wickelgren, 1965). Mean overall error scores for the 15 critical trials were quite similar for the test and control groups [7.75 $(\mathrm{SD}=5.61)$ and $5.90(\mathrm{SD}=4.90)$, respectively]. A t test using a $\sqrt{\mathrm{x}+.5}$ transform of the overall error scores for these trials showed no significant difference between the two groups $[t(38)=1.41, p>.05]$. The greater frequency of homograph intrusions, then, cannot be attributed to a generally higher error rate for test group subjects. As a further check, errors were classified as homograph intrusions, other intrusions, and omissions. For the test group these classes contained 40,52 , and 68 instances, respectively. For the control group these figures were 10,48 , and 60 . Expressed as a percentage of total errors, the test group made $25 \%$ homograph intrusions, while the control group made $8.5 \%$.

\section{Discussion}

As was the case for homophones in Experiment I, homographs appear to activate multiple semantic representations that retain sufficient strength in memory to intrude into the recall of related material encountered some time after homograph presentation. Again, this occurred even in those cases where different forms of the homograph had been selected for recall on previous context lists. As in Experiment I, the interval between presentation and intrusion appears sufficiently long, minimally $30 \mathrm{sec}$, to eliminate the possibiltiy that a purely sensory trace (in this case, a visual trace) could have persisted and been responsible for the effect.

\section{GENERAL DISCUSSION}

What mechanism could be responsible for the appearance in recall of the present intrusions? Current models of word recognition and encoding (e.g., Morton, 1970) suggest that verbal stimuli automatically activate stored representations in memory (logogens) that are sensitive to the particular combinations of physical features present in words. One logogen is said to exist for each word in one's vocabulary and to consist of a locus for the convergence of the graphic, phonemic, and semantic features that define the word. Thus, in addition to the activation received from actual physical input, a logogen is also presumed to be activated by the presentation of related words and context to the extent that this material shares semantic features with the unit in question. Activation from both these sources is said to be combined additively by the logogen and, to the degree that this activation increases, the graphic, phonemic, and semantic features comprising the logogen become more salient in the memory system.

Processing of information beyond this initial stage of activation depends on the selection and transfer of logogen representations to an operating or short-term memory, and it is presumably at this latter point that one becomes aware of the particular word selected. The availability of a logogen for transfer depends on two factors: first, on the amount of activation it has reeieved 
and, second, on a threshold value set by the frequency of occurrence in English of the word it represents. The more common the word, the lower the threshold and the less activation is required for the logogen to pass threshold and become available for transfer.

It is suggested that, in the case of homographs and homophones, the dual meanings of the word are represented in memory as separate logogens with a common set of graphic (phonemic) features but differing in phonemic (graphic) and semantic features. Both feature complexes are equally activated by the physical features of the homophone or homograph when it is presented. Due to the additional activation of its semantic features received from words on the context trial, however, the logogen for the appropriate meaning is more highly activated than its alternate, and only this meaning is transferred to operational memory. Activation of the alternative meaning logogen and the set of semantic and physical features defining it, however, persists for some time after presentation.

When producing recall for a particular triad, it is assumed that the subject examines all traces in operational memory, tests their semantic coding against the category name of the material presented on the current trial, and selects for recall those category members most recently presented. In the event that three category members are not available in active memory and the subject is required to produce three words in recall, the logogen system may also be interrogated. Logogen thresholds are disregarded and only the absolute amount of activation assessed. Semantic representations of those logogens most highly activated are selected and their features compared with the semantic requirements of the current category. Words whose features match are included in recall. In the case of the alternative encoding of homophones and homographs, then, intrusions occur when this secondary search is conducted, and the residual activation of the alternative meaning logogen boosts its probability of selection for inclusion in recall.

Hogaboam and Perfetti (1975) have recently presented evidence indicating that alternate meanings of an ambiguous word may or may not be retrieved, depending on the context in which the word is embedded and the relative dominance of the alternate forms of the word. They suggest that if context biases the dominant form of the word, only that form will be retrieved; if the nondominant form is biased, both meanings will be retrieved.

In their study, form dominance was first determined by presenting subjects with ambiguous words in a free association task and classifying their responses to each word as belonging to one meaning or the other. The meaning to which the bulk of the responses were related was designated as dominant. Words were then presented in sentences biasing one form of the word or the other. When the dominant form of the word was biased, subjects were slower in determining that the word had an alternative meaning than when the nondominant form was biased.

Hogaboarn and Perfetti propose an ordered search model for the encoding of ambiguous words in which the dominant meaning is retrieved first regardless of context. If it matches context, no further meanings are retrieved. Thus, when the dominant form is biased by context, retrieval of the alternate meaning is delayed and latency of the alternate meaning decision is prolonged.

The ordered search hypothesis suggests that homophone and homograph intrusions should only be observed in the current paradigm when context material biases the nondominant form of the word. Only in this case should both meanings be retrieved and the alternate form of the word intrude into later recall. To test this hypothesis, norms for homophones (Galbraith \& Taschman, 1969) and homographs (Cramer, 1970) were consulted for the dominance levels of the stimuli used in the current experiments, and the frequency of intrusion under the two biasing conditions was determined.

In the case of homophones, norms for eight words were available, five of which had been presented biased by context toward the nondominant form (BEET, HOUR, AUNT, HYMN, and KNIGHT) and three for which the context bias had been for the dominant form (ATE, WEAK, and SUN). The former produced an average of 2.0 intrusions of their alternate form by the test group, compared to an average of 1.0 intrusions of that form by the control group. Words where the dominant form had been biased produced an average of 1.8 intrusions by the test group and .8 intrusions by the control group.

For homographs, norms were available for only six words. Four had been presented in context biasing the nondominant form (REFUSE, ENTRANCE, INCENSE, and DOVE) and two context biasing the dominant form (LEAD and BASS). Both types produced an average of 2.0 intrusions by the test group and .5 intrusions by the control group.

Taken together, these results indicate that the differences in retrieval time for dominant and nondominant forms of words noted by Hogaboam and Perfetti (1975) are not reflected in the intrusion data in the current experiments. The retrieval time data may reflect differences in logogen thresholds for the alternate forms of ambiguous words based on word frequency. Galbraith and Taschman (1969) have shown a strong correlation between word frequency and association dominance measures. It would appear, however, that regardless of the time necessary to bring an alternate form of a word to consciousness, both meanings of a word are initially activated in the logogen system. This activation apparently persists long enough to influence the in. trusion patterns generated by the secondary search process outlined above. 


\section{REFERENCE NOTE}

1. Schvanavelt, R. W., Meyer, D. E., \& Becker, C. A. Contextual constraints on ambiguous word recognition. Paper presented at the meeting of the Psychonomic Society, Boston, 1974.

\section{REFERENCES}

Conrad, C. Context effects in sentence comprehension: A study of the subjective lexicon. Memory \& Cognition, 1974, 2, 130-138.

Cramer. P. A study of homographs. In L. Postman \& G. Keppel (Eds.), Norms of word association. New York: Academic Press, 1970.

Crowder, R. G., \& Morton, J. Precategorical acoustic storage (PAS). Perception \& Psychophysics, 1969, 5, 237.238.

Eriksen, C. W., \& Johnson, H. J. Storage and decay characteristics of non-attended auditory stimuli. Journal of Experimental Psychology, 1964, 68, 28-36.

Galbraith, G. G., \& Taschman, C. S. Homophone units: A normative and methodological investigation of the strength of component elements. Joumal of Verbal Learning and Verbal Behavior, 1969, 8, 737-744.

Hogaboam, T. W., \& Perfetti, C. A. Lexical ambiguity and sentence comprehension. Journal of Verbal Learning and Verbal Behavior, 1975, 14, 265-274.

LASHLEY, K. S. The problem of serial order in behavior. In L. A. Jeffress (Ed.), Cerebral mechanisms in behavior. New York: Wiley, 1951.
Light, L. L., \& Carter-Sobell, L. Effects of changed semantic context on recognition memory. Joumal of Verbal Learning and Verbal Behavior, 1970, 9, 1-11.

Myers, J. L. Fundamentals of experimental design. Boston: Allyn \& Bacon, 1966.

Morton, J. A functional model for memory. In D. A. Norman (Ed.), Models of human memory. New York: Academic Press, 1970.

Posner, M. 1., \& Rossman, E. Effect of size and location of informational transforms upon short-term retention. Journal of Experimental Psychology, 1965, 70, 496-505.

WARREn, R. E. Stimulus encoding and memory. Journal of Experimental Psychology, 1972, 94, 90-100.

WARREN, R. E. Association. directionality and stimulus encoding. Joumal of Experimental Psychology, 1974, 102, 151-158.

WhItfoRd, H. C. A dictionary of American homophones and homographs. New York: Teachers College Press, $1 \% 66$.

Wickelgren, W. A. Acoustic similarity and retroactive interference in short-term memory. Journal of Verbal Learning and Verbal Behavior, 1965, 4, 53-61.

Wickens. D. D. Encoding categories of words: An empirical approach to meaning. Psychological Review, 1970, 77, 1-15.

(Received for publication October 24, 1975; revision accepted February $4,1976$. 